\title{
Lizard Epidermal Gland Secretions. II. Chemical Characterization of the Generation Gland Secretion of the Sungazer, Cordylus giganteus
}

Stefan Louw, Ben V. Burger, Maritha Le Roux, and Johannes H. Van Wyk.

Laboratory for Ecological Chemistry, Department of Chemistry and Polymer Science, and Ecophysiology Laboratory, Department of Botany and Zoology, Stellenbosch University, Stellenbosch, 7600, South Africa.

\begin{abstract}
In lizards, the epidermal glands of the femoral and precloacal regions are involved in the production of semiochemicals. In addition to its femoral glands, the giant girdled lizard, or sungazer, Cordylus giganteus, which is endemic to South Africa, has generation glands as an additional potential source of semiochemicals. These epidermal glands are described as glandular scales that overlay the femoral glands and are included in the normal epidermal profile located in the femoral (thigh) and anterior antebrachial (fore-leg) regions of the male sungazer.

GC-MS analysis of the generation gland secretions and the trimethylsilyl derivatives of some of the steroidal constituents was employed to identify 59 constituents, including alkenes, carboxylic acids, alcohols, ketones, aldehydes, esters, amides, nitriles, and steroids. The quantitative differences of the volatile constituents of the fore- and hind-leg generation glands were compared between individuals. This is the first report on the chemical composition of generation glandular material of lizards.
\end{abstract}

Several potential sources of pheromones in lizards have been described, including epidermal and cloacal glands and the blood-skin barrier.(1) A comprehensive review of the natural products originating from the integument of reptiles, including a summary of the chemicals secreted from the femoral (thigh) and precloacal (preanal) glands of a number of lizard species, was recently published.(2) The chemical characterization of the secretion of the femoral glands of the giant girdled lizard, or sungazer, Cordylus giganteus (Squamata, Cordylidae), located in the ventral femoral region, has also been reported.(2, 3) López and co-workers(4-7) recently summarized the potential functions of femoral gland semiochemicals, which could, for example, include mate choice, male-male competition, and interspecific recognition.

In addition to femoral glands, cordylid lizards have holocrine secretory cells located in the beta-layer of the epidermis, termed generation glands, $(8,9)$ which may occur in different body locations, for example, in the femoral, precloacal, antebrachial (fore-arm), and dorsal epidermal regions.(10) In most cases, the glandular material is stacked as a series of beta-layers.(10) In the case of $C$. giganteus, only males have generation glands, as patches of "glandular scales" anterior to the single row of femoral gland pores and on the ventral aspect of the fore-arm region (Figure 1).(10) In other cordylid species, females may also possess generation glands, the number which may vary according to geographical region. $(11,12)$

It has been suggested that the generation glands could have a semiochemical function in combination with other sources such as the femoral glands. $(12,13)$ The purpose of this study was to identify the volatile constituents secreted from the generation glands by GC-MS analysis of the secretion and the trimethylsilyl derivatives of some of its constituents. Additionally, the quantitative differences of the volatile constituents of the fore- and hind-leg generation glands were compared between individuals. The histology of the generation glands of $C$. giganteus is also briefly described. 


\section{Results and Discussion}

\section{Basic Histology}

In Figure 1 the generation glands in the ventral femoral region as well as the fore-leg antebrachial region can be clearly discerned from the normal epidermal scales. The histological profiles of both the femoral and generation gland (Figure 2) correspond to the description given by Van Wyk and Mouton.(10) The stacked beta-layer generations are observed in the generation glands located in the femoral region (Figure 2).

Typical of the beta-type generation glands is the absence of the outer oberhautchen layer, indicating that the outer layer of the generation series is exposed on a continuous basis. Although the generation glands on the fore-legs appear more swollen than those in the ventral femoral region, histological appearance is similar and the bulging is created by the underlying enlarged epidermal plates.(10)

\section{Chemical Characterization}

GC-MS analyses of the dichloromethane extracts of the glandular material showed that the samples collected from the fore- and hind-legs were qualitatively identical. The compounds identified in the material collected from the generation glands of $C$. giganteus are listed in Table 1 . Of the 168 chromatographic peaks observed in the GC flame ionization detector (FID) analyses, 59 components, constituting more than $92 \%$ of the total amount of the detected compounds, could be analyzed with sufficient sensitivity utilizing GC-MS to yield mass spectra amenable to MS interpretation and comparison with Wiley, National Bureau of Standards (NBS), National Institute of Standards and Technology (NIST), and the in-house mass spectra libraries.

A typical GC-FID chromatogram is depicted in Figure 3. The structures of the majority of these compounds were confirmed by GC coelution with authentic reference compounds. Quantitative GC-FID analyses using solventless sample introduction revealed quantitative differences between fore- and hind-leg samples, as well as between individuals. The results from the quantitative analyses are summarized in Table 1. The EI-MS of constituents $\mathbf{5}$ and $\mathbf{7}$ displayed prominent ions corresponding to the general formulas $\left[\mathrm{C}_{n} \mathrm{H}_{2 n-1}\right]^{+}$and $\left[\mathrm{C}_{n} \mathrm{H}_{2 n}\right]^{+}$and decreasing in abundance with increasing mass, characteristic of monounsaturated alkenes and saturated aliphatic alcohols.(14)

Comparison of the mass spectra of these constituents with the available mass spectral libraries indicated that they could be either 1-alkenes or 1-alcohols. Although no molecular ions were present in their mass spectra, they were identified as 1-tetradecene (5) and 1-pentadecene (7) by co-injection of the generation gland extract with authentic synthetic samples of these compounds. Alkenes have been found in the skin of some lizards and snakes, but not in the secretions of lizards.(2) The occurrence of alkenes in the generation gland secretions could, however, be due to the fact that the generation glands are in fact glandular scales, forming part of the lizard's skin.

A number of additional compound classes, commonly found in lizard secretions,(2) including the femoral gland secretion of $C$. giganteus,(3) were also identified in its generation gland secretions, i.e., the $C_{9}, C_{10}$, and $C_{12-22}$ unbranched saturated and unsaturated fatty acids $3,4,8,11,15,18,24,26,27,32,34,37,40,42$, and 44 , the $C_{12}$, $C_{14}, C_{15}$, and $C_{16}$ primary alcohols $6, \mathbf{1 2}, \mathbf{1 6}$, and $\mathbf{2 0}$, the $C_{14}, C_{15}$, and $C_{17}$ methyl ketones $\mathbf{9}, \mathbf{1 3}$, and $\mathbf{2 2}$, the $C_{9}, C_{10}$, and $C_{14-17}$ saturated and unsaturated aldehydes $1,2,10,14,17$, and 19 , the methyl- $C_{16}$ and dodecyl- $C_{16}$ saturated and unsaturated esters $\mathbf{2 3}, \mathbf{4 7}$, and $\mathbf{4 8}, 11$ steroids (49-59), squalene (46), and a $y$-lactone, hexadecan-4-olide (29). It is interesting to note that cholesterol, one of the major components identified in the femoral gland secretions of $C$. giganteus,(3) does not occur in the generation gland material.

Hexadecanoic acid (26) is the major component of all the generation gland secretions analyzed. The identification of steroids $\mathbf{4 9 - 5 8}$ could not be confirmed by retention time comparison, due to the unavailability of standards. However, in some cases additional diagnostic information was obtained by the interpretation of the El-mass spectra of these steroids employing published MS data. An interesting application of this technique is illustrated by the identification of the three cholestan-3-ol isomers $\mathbf{4 9}, \mathbf{5 0}$, and $\mathbf{5 1}$, the mass spectra of which did not allow unambiguous differentiation between the three isomers.

However, some differences exist between the isomers with respect to the relative abundance of the ions formed by the elimination of water from the molecular ion due to the influence of the compounds' configuration on the mechanism of this elimination. $(15,16)$ In general, the mass spectra of $\mathrm{C}_{17}$-substituted steroids with cis-A/B ring junctions $(5 \beta-\mathrm{H})$ have prominent $\left[\mathrm{M}-\mathrm{H}_{2} \mathrm{O}\right]^{++}$ions, whereas the corresponding mass spectra of steroids with trans- 
A/B ring junctions $(5 \alpha-H)$ have $\left[\mathrm{M}-\mathrm{H}_{2} \mathrm{O}\right]^{*+}$ ions with low relative abundances.(15) From this information it was deduced that constituent $\mathbf{4 9}$ is a $5 \beta-\mathrm{H}$ isomer of cholestan-3-ol and that constituents $\mathbf{5 0}$ and $\mathbf{5 1}$ are the $5 \alpha-\mathrm{H}$ isomers. Comparison of the mass spectra of the TMS derivatives of these constituents with those in mass spectra libraries revealed that constituent $\mathbf{4 9}$ is probably $5 \beta$-cholestan-3 $\alpha$-ol, while confirming that constituents $\mathbf{5 0}$ and $\mathbf{5 1}$ are the two $5 \alpha-\mathrm{H}$ isomers of cholestan-3-ol.

The C-3 configuration of the latter two constituents could not be determined. The sterols $\mathbf{5 4}, \mathbf{5 5}, \mathbf{5 6}$, and $\mathbf{5 8}$, the identities of which were not confirmed by retention time comparison with standards, were positively identified on the basis of the good correlation of their mass spectra, as well as the mass spectra of their TMS derivatives, with those of the mass spectra libraries. Constituents 52, 53, and $\mathbf{5 7}$ were tentatively identified as 3-ethoxycholestane, cholestan-2/3-one, and cholest-4-en-3-one, respectively, by MS interpretation and comparison of their El-mass spectra with mass spectra libraries, but their identities could not be confirmed.

The aliphatic nitriles hexadecanitrile (21) and octadecanitrile (30) and the aliphatic amides pentadecanamide (28), (Z)-9-hexadecenamide (33), hexadecanamide (35), heptadecanamide (38), octadecanamide (41), nonadecanamide (43), and icosanamide (45) have not been found in the secretions of any lizard species, although long-chain aliphatic amides have been identified in secretions from the scent glands of two snake species, Dumeril's ground boa, Acrantophis dumerili,(17) and the western diamondback rattlesnake, Crotalus atrox.(18) The scent glands produce secretions that contain chemicals that are, for example, used as allomones to repel predators.(2)

A few short-chain nitriles have been identified in the sternal gland secretions used by the male koala, Phascolarctos cinereus, for territorial marking.(19) Even though GC-MS analysis yielded good mass spectra for constituents 25, 31, 36, and 39, these constituents could not be identified by MS library comparison or the interpretation of their mass spectra, due to the paucity of relevant mass spectrometric information. The present investigation showed that the generation glands produce more diverse chemicals than the femoral glands, including groups of compounds (e.g., nitriles and amides) that are absent from the femoral gland secretions.(3)C. giganteus is the only cordylid that is recognized as a terrestrial grassland species, and the unique presence of generation glands on the fore-legs(10) may relate to marking of the grass substrate.

The fact that the chemical composition of the hind- and fore-leg generation glands is qualitatively identical supports the assumption that the glands on the fore-legs not only constitute a functional increase in the secretion volume but might also facilitate effective depositing of glandular material in the grassland environment. Although the quantities of chemicals produced by the generation glands differ between individual lizards, no pattern could be found in these differences (Table 1). The information made available in the present study should facilitate investigations into the semiochemical communication of $C$. giganteus and other species.

\section{Experimental Section}

\section{General Experimental Procedures}

All Pyrex glassware used for the chemical analysis was thoroughly cleaned with $\mathrm{H}_{2} \mathrm{O}$ and acetone and heated to 500 ${ }^{\circ} \mathrm{C}$ to remove any residual organic material. Dichloromethane (Fluka, residue analysis grade) was used for extraction of organic material from collected samples. Syringes were cleaned with the same solvent. GC analyses were performed on a Carlo Erba 5300 gas chromatograph, using Borwin Intuitive Chromatography software, version 1.22, for data acquisition. The determination of the absolute abundance of constituents was done with an HP 5890 Series II GC, equipped with an autosampler.

Agilent Chemstation software, version A.09.01, was used for instrument control and data acquisition. These instruments were equipped with FIDs and split/splitless inlet systems, and their injectors and detectors were operated at 220 and $280^{\circ} \mathrm{C}$, respectively. Glass capillary columns ( $40 \mathrm{~m} \times 0.3 \mathrm{~mm}$ i.d.) were coated with PS-089-OH, a silanol-terminated (95\%)-methyl-(5\%)-phenylpolysiloxane copolymer, at a film thickness of $0.25 \mu \mathrm{m}$. Helium was used as carrier gas at a linear flow velocity of $28.6 \mathrm{~cm} / \mathrm{s}$. Samples were injected in the split mode using a split ratio of 1:10. The sample constituents were thermally focused on the column at a temperature of $30^{\circ} \mathrm{C}$, after which the column was heated ballistically to $40^{\circ} \mathrm{C}$ and then programmed at $2{ }^{\circ} \mathrm{C} / \mathrm{min}$ from 40 to $280^{\circ} \mathrm{C}$ (hold $60 \mathrm{~min}$ ). 
EI-MS data were acquired at $70 \mathrm{eV}$ on a Carlo Erba QMD $1000 \mathrm{GC}-\mathrm{MS}$ instrument, using the above-mentioned column and conditions, with $\mathrm{He}$ as carrier gas at an average linear velocity of $28.6 \mathrm{~cm} / \mathrm{s}$. Steroid derivatives were analyzed using a mass range of $\mathrm{m} / \mathrm{z} 25$ to 550 . Ion source and interface temperatures of 200 and $250{ }^{\circ} \mathrm{C}$, respectively, were used for all analyses. Some GC-MS analyses were done on a Fisons MD-800 instrument using the parameters specified above.

NMR spectra of synthetic reference compounds were recorded in $\mathrm{CDCl}_{3}$ on Varian Unity INOVA $600 \mathrm{NMR}$, Varian Unity INOVA 400 NMR, and Varian 300 VNMRS instruments (Varian, Palo Alto, USA). Chemical shifts are given in parts per million ( $\delta$ ) relative to $\mathrm{CHCl}_{3}$ (7.26 and 77.04 ppm for ${ }^{1} \mathrm{H}$ and ${ }^{13} \mathrm{C} N M R$, respectively).

\section{Histology of the Generation Glands}

Skin biopsies were obtained from specimens collected for studies regarding the reproductive cycle of these lizards. (20) Biopsies were subjected to routine histological procedures using paraffin wax (Merck, Histosec, 56-58 ${ }^{\circ} \mathrm{C}$ ) as embedding medium. Sections $(6-10 \mu \mathrm{m})$ were cut with a rotary microtome and stained with hematoxylin (Merck) and eosin yellowish (Saarchem).(21)

\section{Collection and Sample Preparation}

Generation gland secretions were collected individually from the fore- and hind-legs of 10 adult male lizards in a study population on a farm in the Lindley district (Free State Province, South Africa; $28^{\circ} 01^{\prime} \mathrm{S}, 28^{\circ} 05^{\prime} \mathrm{E}$ ) during April 1998. The secretions were collected by removing the external layers (reminiscent of shed skin) of the glandular scales on the fore- and hind-legs of the lizards, using a pair of sharp-tipped stainless steel forceps. The collected material was transported to Stellenbosch at $-10^{\circ} \mathrm{C}$ and stored at $-70^{\circ} \mathrm{C}$ until processed for analysis. The organic constituents were extracted from individually collected secretions with $100 \mu \mathrm{L}$ of DCM.

The extracts were subsequently centrifuged and concentrated to ca. $10 \mu \mathrm{L}$ by slow evaporation of the solvent at room temperature in a $\mathrm{N}_{2}$ atmosphere.(22) Samples of 0.2 to $1.0 \mu \mathrm{L}$ of these concentrated extracts were used per analysis for qualitative GC-MS analyses. Quantitative GC determination of the relative abundance of the constituents of the secretions of the group of males was performed using solventless sample introduction(23) of the raw secretion. For the determination of the absolute abundance of each constituent in the generation gland secretion, extracts of the secretions from the fore- and hind-legs of a male lizard were prepared by extracting 11.3 and $10.3 \mathrm{mg}$ of the respective secretions with four portions of $200 \mu \mathrm{L}$ of DCM each.

Each extract was slowly evaporated to dryness in an inert atmosphere at $22^{\circ} \mathrm{C}$, and the residual material was dissolved in $20 \mu \mathrm{L}$ of an internal standard solution containing $35.9 \mu \mathrm{g}$ of octadecane/mL in DCM. Quantities of $2 \mu \mathrm{L}$ of each of these solutions were used for quantitative GC determinations. Absolute constituent amounts were calculated proportional to that of the internal standard, using their chromatographic peak area ratios.

\section{Trimethylsilyl (TMS) Derivatives}

An extract of the generation gland material was concentrated in a Reacti-Vial left uncapped in a purified $\mathrm{N}_{2}$ atmosphere to yield approximately $1 \mathrm{mg}$ of solvent-free material. TMS derivatizations(24) were performed as previously described.(3)

\section{Reference Compounds}

Most of the reference compounds used to confirm the identity of the constituents of the generation gland secretions by retention time comparison were obtained commercially. Hexadecanitrile (21), octadecanitrile (30), pentadecanamide (28), (Z)-9-hexadecenamide (33), hexadecanamide (35), octadecanamide (41), icosanamide (45), dodecyl (Z)-9-hexadecenoate (47), and dodecyl hexadecanoate (48) were synthesized from authentic starting materials according to procedures exemplified by the syntheses of $\mathbf{2 1}, \mathbf{2 8}$, and $\mathbf{4 7}$. (For other syntheses and the spectroscopic data of other compounds, see the Supporting Information.)

\section{Hexadecanitrile (21)}

was synthesized from 1-bromopentadecane by substitution of the bromine with cyanide. $(25,26)$ A mixture of 1 bromopentadecane $(0.48 \mathrm{~g}, 1.65 \mathrm{mmol}), \mathrm{NaCN}(0.101 \mathrm{~g}, 2.06 \mathrm{mmol})$, and triethyleneglycol (ca. $1 \mathrm{~mL})$ was stirred and slowly heated to $140{ }^{\circ} \mathrm{C}$. After stirring the reaction mixture at this temperature for another $3 \mathrm{~h}$, the mixture was added to $\mathrm{H}_{2} \mathrm{O}(10 \mathrm{~mL})$, and the organic product was extracted with $\mathrm{CHCl}_{3}$. 
The extract was washed with $\mathrm{H}_{2} \mathrm{O}$ to neutral $\mathrm{pH}$ and dried on anhydrous $\mathrm{MgSO}_{4}$, and the organic product was isolated in the usual manner to yield pure (GC-MS) hexadecanitrile $(0.25 \mathrm{~g}, 64 \%):{ }^{13} \mathrm{C} \mathrm{NMR}\left(100 \mathrm{MHz}, \mathrm{CDCl}_{3}\right) \delta 14.06$ (C-16), 17.06 (C-2), 22.65 (C-15), 25.35 (C-3), 28.63 (C-4), 28.73 (C-5), 29.27 (C-13), $29.33\left(\mathrm{CH}_{2}\right), 29.47\left(\mathrm{CH}_{2}\right), 29.56$ $\left(\mathrm{CH}_{2}\right), 29.61\left(\mathrm{CH}_{2}\right), 29.62\left(\mathrm{CH}_{2}\right), 29.64\left(\mathrm{CH}_{2}\right), 29.65\left(\mathrm{CH}_{2}\right), 31.89$ (C-14), $119.75(\mathrm{C}-1)$; EIMS m/z 222 (2), 208 (12), 194 (17), 180 (13), 166 (11), 152 (13), 138 (21), 124 (41), 110 (70), 97 (82), 82 (42), 69 (44), 57 (86), 43 (100), 29 (45).

\section{Pentadecanamide (28)}

was prepared from pentadecanoic acid via the corresponding acid chloride. $(25,26)$ Pentadecanoic acid $(0.20 \mathrm{~g}, 0.825$ mmol) was refluxed with thionyl chloride $(1 \mathrm{~mL}, 13.8 \mathrm{mmol})$ for $30 \mathrm{~min}$, after which the remaining thionyl chloride was distilled off. The acid chloride was cooled in an ice bath and treated with concentrated ammonia solution $(3 \mathrm{~mL}$, 25\%). The resulting solid material was filtered and washed with $\mathrm{H}_{2} \mathrm{O}$ containing a small percentage of EtOH.

The product was dried at room temperature on filtration paper, yielding the pure (GC-MS) pentadecanamide $(0.18 \mathrm{~g}$, 90\%): ${ }^{1} \mathrm{H}$ NMR $\left(400 \mathrm{MHz}, \mathrm{CDCl}_{3}\right) \delta 0.87\left(3 \mathrm{H}, \mathrm{t}, J=6.8, \mathrm{CH}_{3}\right), 1.24(22 \mathrm{H}, \mathrm{m}), 1.62(2 \mathrm{H}, \mathrm{m}, \mathrm{H}-3), 2.21(2 \mathrm{H}, \mathrm{t}, J=7.8, \mathrm{H}-2)$, $5.45(1 \mathrm{H}, \mathrm{s}, \mathrm{NH}), 5.82(1 \mathrm{H}, \mathrm{s}, \mathrm{NH}) ;{ }^{13} \mathrm{C} \mathrm{NMR}\left(\mathrm{CDCl}_{3}, 100 \mathrm{MHz}\right) \delta 14.14$ (C-15), $22.71(\mathrm{C}-14), 25.55$ (C-3), 29.25 (C-4), $29.35(\mathrm{C}-5), 29.38(\mathrm{C}-12), 29.49\left(\mathrm{CH}_{2}\right), 29.63\left(\mathrm{CH}_{2}\right), 29.67\left(\mathrm{CH}_{2}\right), 29.67\left(\mathrm{CH}_{2}\right), 29.69\left(\mathrm{CH}_{2}\right), 29.71\left(\mathrm{CH}_{2}\right), 31.95(\mathrm{C}-13)$, 36.00 (C-2), 176.17 (C-1); EIMS m/z $241\left(1, \mathrm{M}^{+}\right), 212$ (2), 198 (3), 184 (2), 170 (2), 156 (3), 142 (3), 128 (5), 114 (5), 97 (7), 86 (8), $72(36), 59(100), 43(35), 29(8)$.

\section{Dodecyl (Z)-9-hexadecenoate (47)}

was synthesized by refluxing a mixture of (Z)-9-hexadecenoic acid ( $25.4 \mathrm{mg}, 0.01 \mathrm{mmol}$ ), dodecanol (18.4 mg, 0.01 $\mathrm{mmol})$, and pTSA monohydrate $(1 \mathrm{mg})$ in benzene $(20 \mathrm{~mL})$ for $30 \mathrm{~h} .(25)$

The product was washed twice with $\mathrm{H}_{2} \mathrm{O}$ and dried, and the solvent was removed on a rotary evaporator to yield practically pure (GC-MS) dodecyl (Z)-9-hexadecenoate in quantitative yield: ${ }^{13} \mathrm{C} \mathrm{NMR}\left(100 \mathrm{MHz}, \mathrm{CDCl}_{3}\right) \delta 14.13$ (C12'), 14.15 (C-16), 22.69 (C-15), $22.72\left(\mathrm{C}^{\prime}-11^{\prime}\right), 25.06$ (C-3), 25.97 (C-3'), 27.20 (C-11), 27.26 (C-8), 28.69 (C-2'), 29.02 (C-4), $29.14\left(\mathrm{CH}_{2}\right), 29.17\left(\mathrm{CH}_{2}\right), 29.21\left(\mathrm{CH}_{2}\right), 29.29\left(\mathrm{CH}_{2}\right), 29.38\left(\mathrm{CH}_{2}\right), 29.56\left(\mathrm{CH}_{2}\right), 29.61\left(\mathrm{CH}_{2}\right), 29.67\left(\mathrm{CH}_{2}\right), 29.68$ $\left(\mathrm{CH}_{2}\right), 29.72\left(\mathrm{CH}_{2}\right), 29.77\left(\mathrm{CH}_{2}\right), 31.82\left(\mathrm{C}-10^{\prime}\right), 31.95$ (C-14), $34.44(\mathrm{C}-2), 64.45\left(\mathrm{C}-1^{\prime}\right), 129.78(\mathrm{C}-9), 130.01(\mathrm{C}-10)$, 174.03 (C-1); EIMS m/z 422 (1, M+), 255 (8), 236 (40), 194 (14), 152 (31), 125 (19), 111 (43), 98 (57), 97 (77), 83 (85), $71(60), 69$ (95), 57 (90), 43 (79), 41 (57), 29 (24).

\section{Acknowledgment}

This research was supported by Stellenbosch University and the National Research Foundation, Pretoria, South Africa. L. Ruddock is thanked for the collection of secretions.

\section{Supporting Information}

Mass spectrometric data of identified constituents and spectroscopic data of synthesized compounds. This material is available free of charge via the Internet at http://pubs.acs.org. 


\section{Figures}
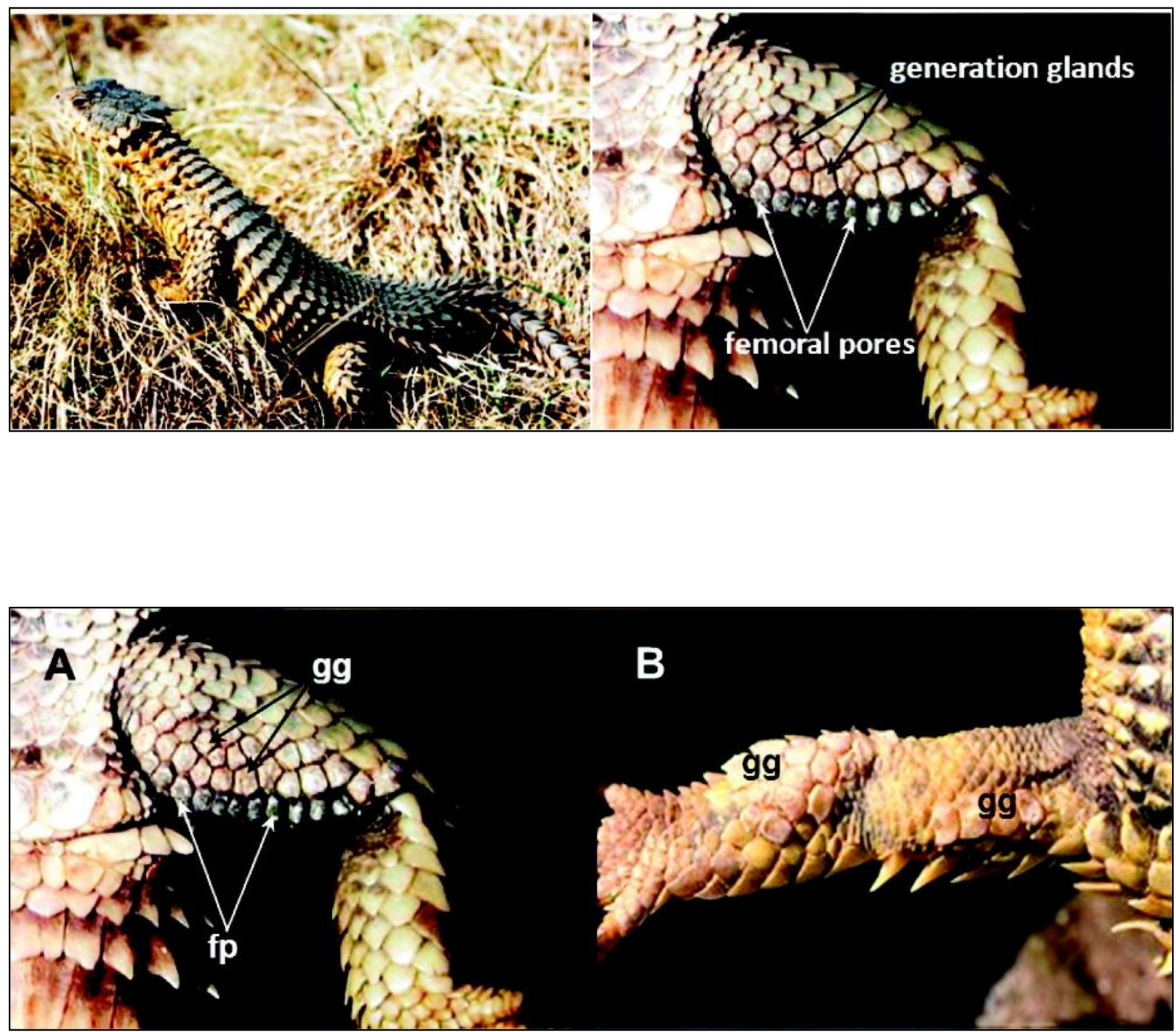

Figure 1. Generation glands in C. giganteus lizards. (A) Ventral view of the hind-leg of a male lizard showing a single row of femoral pores ( $f p$ ) and an anterior patch of generation glands (gg). (B) Ventral view of the fore-leg of a male lizard showing groups of generation glands (gg). 


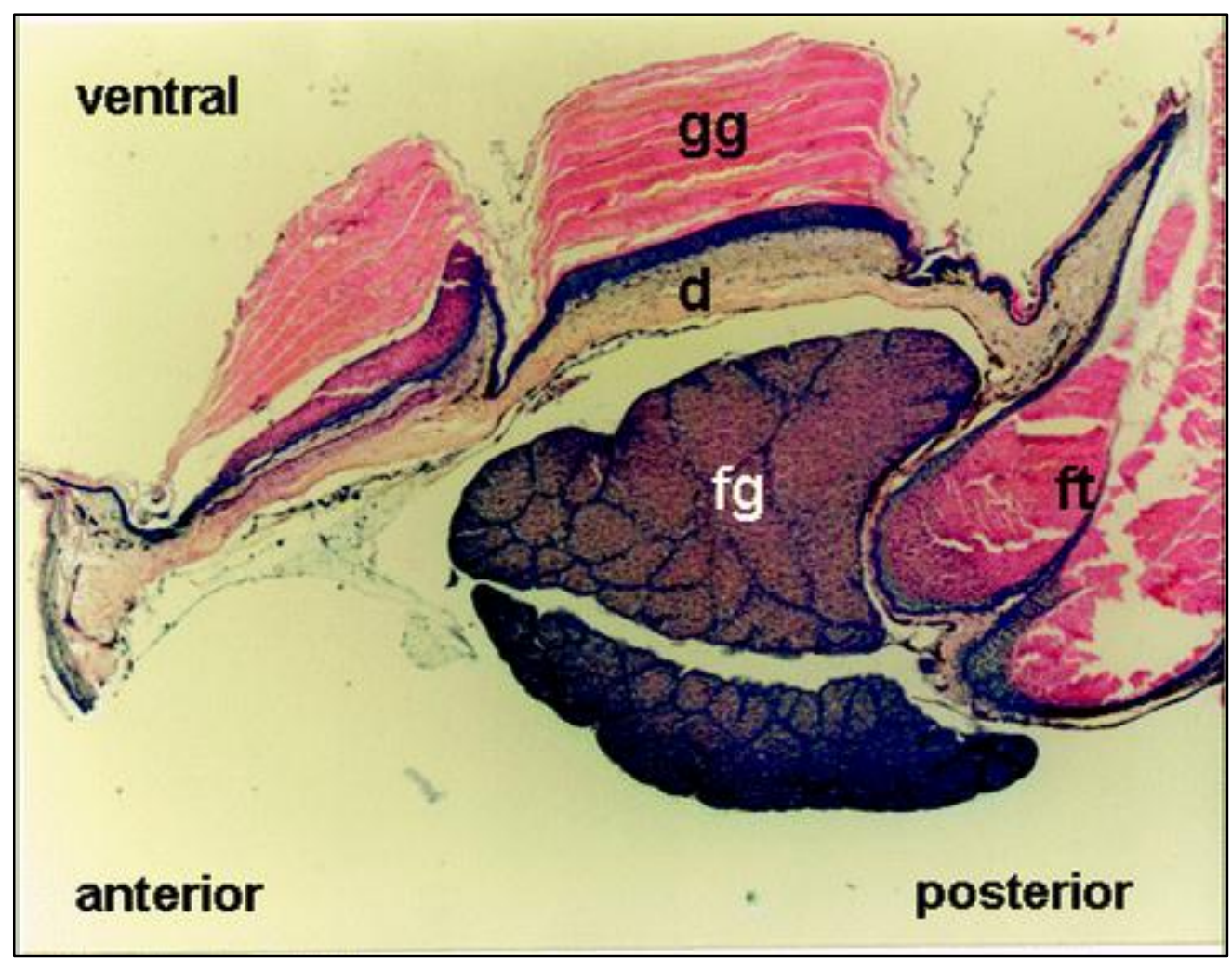

Figure 2. Histological cross-section of the epidermis in the ventral femoral region of an adult male $C$. giganteus. The femoral gland $(\mathrm{fg})$ is located in the dermis $(\mathrm{d})$, and the femoral gland tube $(\mathrm{ft})$ opens on the ventral surface of the femoral region of the hind-leg. The stacked generation layers of the generation gland (gg) overlays the femoral gland as part of the epidermal profile.

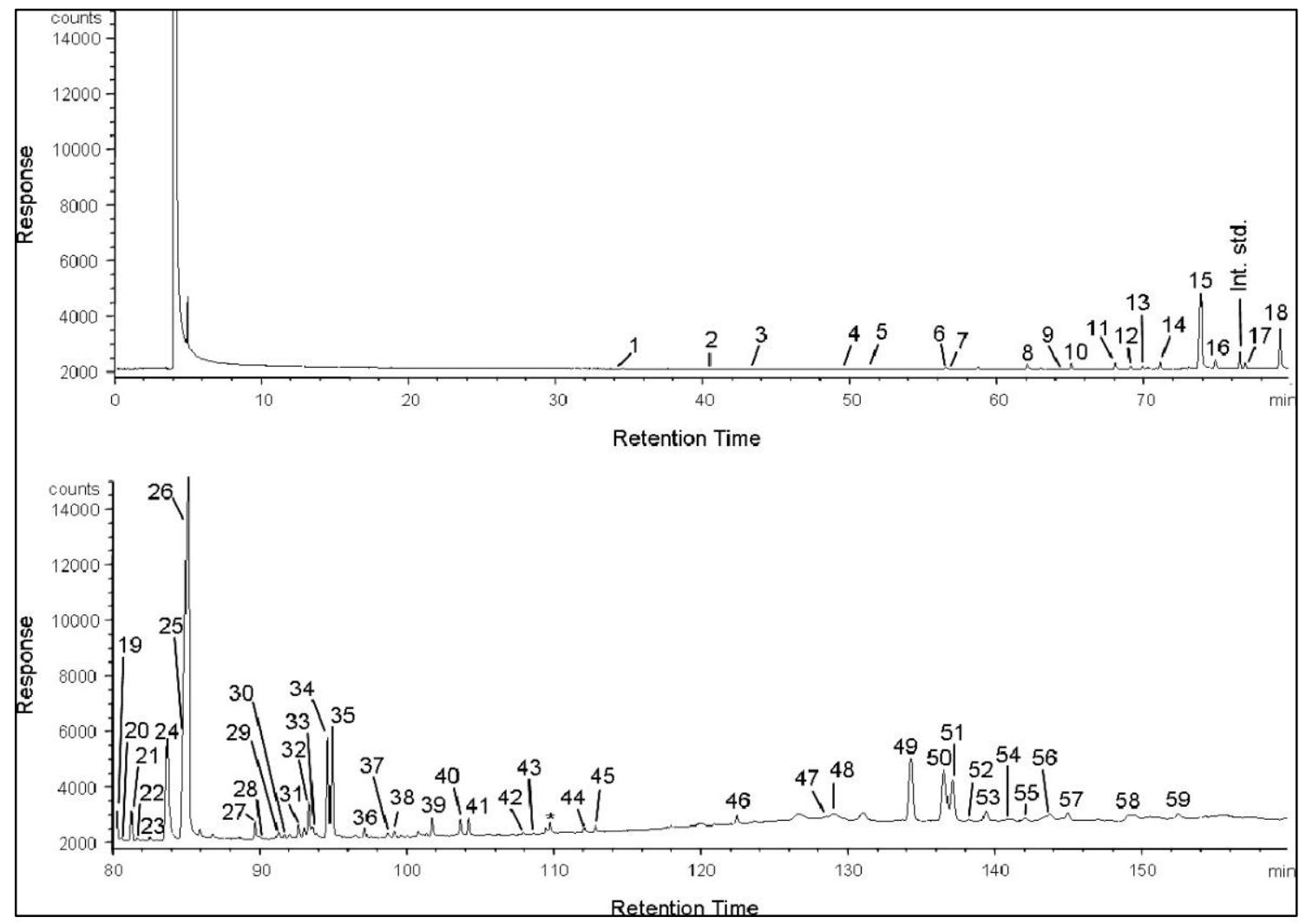

Figure 3. GC-FID chromatogram of an extract of fore-leg generation gland material of a male sungazer, $C$. giganteus. The analytical parameters are given in the text, and the identified compounds are numbered in order of elution from the GC column. *Impurity. 
Tables

Table 1. Constituents Identified in the Generation Gland Secretion of the Male Sungazer, C. giganteus

\begin{tabular}{|c|c|c|c|c|c|c|}
\hline \multirow[b]{2}{*}{ number in Figure $3^{a}$} & \multirow[b]{2}{*}{ constituent } & \multirow[b]{2}{*}{ ident. ${ }^{b}$} & \multicolumn{2}{|c|}{$\begin{array}{l}\text { quantity } \\
\text { (ng/mg) }\end{array}$} & \multicolumn{2}{|c|}{ relative amounts $^{d}$} \\
\hline & & & $\begin{array}{c}\text { fore- } \\
\text { leg }\end{array}$ & $\begin{array}{c}\text { hind- } \\
\text { leg }\end{array}$ & $\begin{array}{c}\text { fore-leg }(n= \\
10)\end{array}$ & $\begin{array}{c}\text { hind-leg }(n= \\
10)\end{array}$ \\
\hline \multicolumn{7}{|l|}{ Alkenes } \\
\hline 5 & 1-tetradecene & $A, B$ & 5 & 2 & $0.09 \pm 0.06$ & $0.02 \pm 0.01$ \\
\hline 7 & 1-pentadecene & $A, B$ & 4 & 4 & $0.09 \pm 0.03$ & $0.04 \pm 0.02$ \\
\hline \multicolumn{7}{|l|}{ Acids } \\
\hline 3 & nonanoic acid & $A, B$ & 2 & 3 & $0.01 \pm 0.00$ & $0.01 \pm 0.01$ \\
\hline 4 & decanoic acid & $A, B$ & 1 & 2 & $0.01 \pm 0.00$ & $<0.005$ \\
\hline 8 & dodecanoic acid & $A, B$ & 33 & 31 & $0.19 \pm 0.08$ & $0.23 \pm 0.12$ \\
\hline 11 & tridecanoic acid & $A, B$ & 40 & 16 & $0.06 \pm 0.03$ & $0.06 \pm 0.07$ \\
\hline 15 & tetradecanoic acid & $A, B$ & 483 & 440 & $2.70 \pm 0.54$ & $2.27 \pm 0.56$ \\
\hline 18 & pentadecanoic acid & $A, B$ & 220 & 164 & $1.36 \pm 0.71$ & $0.84 \pm 0.33$ \\
\hline 24 & (Z)-9-hexadecenoic acid & $A, B$ & 838 & 1488 & $12.16 \pm 6.92$ & $13.75 \pm 4.27$ \\
\hline 26 & hexadecanoic acid & $A, B$ & 3479 & 3971 & $39.32 \pm 3.54$ & $38.30 \pm 3.57$ \\
\hline 27 & heptadecanoic acid & $A, B$ & 88 & 77 & $0.59 \pm 0.26$ & $0.42 \pm 0.18$ \\
\hline 32 & (Z)-9-octadecenoic acid & $A, B$ & 160 & 378 & $2.31 \pm 1.11$ & $2.80 \pm 0.69$ \\
\hline 34 & octadecanoic acid & $A, B$ & 501 & 715 & $6.72 \pm 2.04$ & $5.92 \pm 1.36$ \\
\hline 37 & nonadecanoic acid & $A, C$ & 34 & 29 & $0.01 \pm 0.01$ & $<<0.005$ \\
\hline 40 & icosanoic acid & $A, B$ & 88 & 132 & $0.45 \pm 0.18$ & $0.53 \pm 0.19$ \\
\hline 42 & henicosanoic acid & $A, B$ & 15 & 21 & $0.05 \pm 0.02$ & $0.06 \pm 0.01$ \\
\hline 44 & docosanoic acid & $A, B$ & 28 & 39 & $0.10 \pm 0.07$ & $0.12 \pm 0.05$ \\
\hline \multicolumn{7}{|l|}{ Alcohols } \\
\hline 6 & 1-dodecanol & $A, B$ & 13 & 63 & $0.57 \pm 0.51$ & $1.06 \pm 0.55$ \\
\hline 12 & 1-tetradecanol & $A, B$ & 16 & 6 & $0.13 \pm 0.03$ & $0.05 \pm 0.02$ \\
\hline 16 & 1-pentadecanol & $A, B$ & 45 & 23 & $0.03 \pm 0.01$ & $0.03 \pm 0.01$ \\
\hline 20 & 1-hexadecanol & $A, B$ & 21 & 18 & $0.03 \pm 0.02$ & $0.01 \pm 0.01$ \\
\hline \multicolumn{7}{|l|}{ Ketones } \\
\hline 9 & 2-tetradecanone & $A, C$ & 4 & 3 & $0.01 \pm 0.01$ & $0.01 \pm 0.00$ \\
\hline 13 & 2-pentadecanone & $A, B$ & 12 & 28 & $0.09 \pm 0.04$ & $0.02 \pm 0.01$ \\
\hline 22 & 2-heptadecanone & $A, B$ & 15 & 15 & $0.08 \pm 0.04$ & $0.05 \pm 0.01$ \\
\hline \multicolumn{7}{|l|}{ Aldehydes } \\
\hline 1 & nonanal & $A, B$ & 1 & 1 & $0.02 \pm 0.01$ & $0.01 \pm 0.01$ \\
\hline 2 & decanal & $A, B$ & 2 & 1 & $0.01 \pm 0.01$ & $0.02 \pm 0.04$ \\
\hline 10 & tetradecanal & $A, B$ & 31 & 12 & $0.02 \pm 0.01$ & $0.01 \pm 0.00$ \\
\hline 14 & pentadecanal & $A, C$ & 36 & 12 & $0.03 \pm 0.02$ & $0.03 \pm 0.03$ \\
\hline 17 & hexadecanal & $A, B$ & 28 & 8 & $0.03 \pm 0.07$ & $0.01 \pm 0.00$ \\
\hline 19 & 2-heptadecenal & $A, C, E$ & 145 & 192 & $0.57 \pm 0.86$ & $0.12 \pm 0.16$ \\
\hline \multicolumn{7}{|l|}{ Esters } \\
\hline 23 & methyl hexadecanoate & $A, B$ & 19 & 2 & $0.02 \pm 0.01$ & $0.02 \pm 0.02$ \\
\hline 47 & dodecyl (Z)-9-hexadecenoate & $A, B$ & 29 & 17 & $0.03 \pm 0.02$ & $0.10 \pm 0.06$ \\
\hline 48 & dodecyl hexadecanoate & $A, B$ & 102 & 17 & $0.07 \pm 0.12$ & $0.08 \pm 0.07$ \\
\hline \multicolumn{7}{|l|}{ Nitriles } \\
\hline 21 & hexadecanitrile & $A, B$ & 133 & 62 & $1.84 \pm 0.92$ & $0.41 \pm 0.24$ \\
\hline 30 & octadecanitrile & $A, B$ & 22 & 24 & $0.18 \pm 0.06$ & $0.06 \pm 0.04$ \\
\hline
\end{tabular}




\begin{tabular}{|c|c|c|c|c|c|c|}
\hline \multirow[b]{2}{*}{ number in Figure $3^{a}$} & \multirow[b]{2}{*}{ constituent } & \multirow[b]{2}{*}{ ident. $^{\text {b }}$} & \multicolumn{2}{|c|}{$\begin{array}{l}\text { quantity } \\
\text { (ng/mg) }\end{array}$} & \multicolumn{2}{|c|}{ relative amounts $^{d}$} \\
\hline & & & \begin{tabular}{|c|}
$\begin{array}{c}\text { fore- } \\
\text { leg }\end{array}$ \\
\end{tabular} & $\begin{array}{c}\text { hind- } \\
\text { leg }\end{array}$ & $\begin{array}{c}\text { fore-leg }(n= \\
10)\end{array}$ & $\begin{array}{c}\text { hind-leg }(n= \\
10)\end{array}$ \\
\hline \multicolumn{7}{|l|}{ Amides } \\
\hline 28 & pentadecanamide & $A, B$ & 16 & 15 & $0.12 \pm 0.17$ & $0.05 \pm 0.02$ \\
\hline 33 & (Z)-9-hexadecenamide & $A, B$ & 46 & 80 & $0.79 \pm 0.16$ & $0.73 \pm 0.09$ \\
\hline 35 & hexadecanamide & $A, B$ & 575 & 288 & $0.25 \pm 0.14$ & $0.19 \pm 0.12$ \\
\hline 38 & heptadecanamide & $A, C$ & 34 & 24 & $0.12 \pm 0.10$ & $0.05 \pm 0.04$ \\
\hline 41 & octadecanamide & $A, B$ & 83 & 78 & $0.45 \pm 0.16$ & $0.32 \pm 0.11$ \\
\hline 43 & nonadecanamide & $A, C$ & 11 & 8 & $0.02 \pm 0.01$ & $0.02 \pm 0.00$ \\
\hline 45 & icosanamide & $A, B$ & 32 & 26 & $0.24 \pm 0.09$ & $0.33 \pm 0.12$ \\
\hline \multicolumn{7}{|l|}{ Steroids } \\
\hline 49 & $5 \beta$-cholestan-3 $\alpha$-ol & $A, D$ & 609 & 1099 & $3.81 \pm 1.18$ & $5.16 \pm 1.69$ \\
\hline 50 & $5 \alpha$-cholestan-3 $\alpha / \beta$-ol & $A, D$ & 607 & 770 & $1.86 \pm 0.73$ & $2.02 \pm 0.73$ \\
\hline 51 & 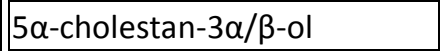 & $A, D$ & 445 & 712 & $1.13 \pm 0.35$ & $1.90 \pm 0.71$ \\
\hline 52 & 3-ethoxycholestane & $A$ & 25 & 18 & $0.10 \pm 0.08$ & $0.08 \pm 0.05$ \\
\hline 53 & cholestan-2/3-one & $A$ & 107 & 17 & $0.07 \pm 0.03$ & $0.17 \pm 0.13$ \\
\hline 54 & 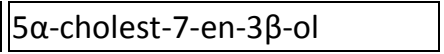 & $A, D$ & 57 & 54 & $0.06 \pm 0.05$ & $0.07 \pm 0.03$ \\
\hline 55 & $5 \beta$-ergostanol & $A, D$ & 45 & 27 & $0.12 \pm 0.05$ & $0.21 \pm 0.07$ \\
\hline 56 & ergost-5-en-3 $\beta$-ol & $A, D$ & 94 & 90 & $0.16 \pm 0.11$ & $0.32 \pm 0.20$ \\
\hline 57 & cholest-4-en-3-one & $A$ & 66 & 169 & $0.11 \pm 0.10$ & $0.17 \pm 0.14$ \\
\hline 58 & $5 \beta$-stigmastanol & $A, D$ & 109 & 38 & $0.03 \pm 0.01$ & $0.05 \pm 0.02$ \\
\hline 59 & lanosterol & $A, B, D$ & 60 & 184 & $0.14 \pm 0.07$ & $0.31 \pm 0.16$ \\
\hline \multicolumn{7}{|l|}{ Miscellaneous } \\
\hline 29 & hexadecane-4-olide & $A, B$ & 43 & 20 & $0.14 \pm 0.07$ & $0.10 \pm 0.09$ \\
\hline 46 & squalene & $A, B$ & 51 & 123 & $0.28 \pm 0.17$ & $0.69 \pm 0.45$ \\
\hline \multicolumn{7}{|l|}{$\begin{array}{l}\text { Unknown } \\
\text { constituents }\end{array}$} \\
\hline 25 & $\begin{array}{l}m / z 39,42,57,69,71,83,85 \\
239\end{array}$ & $A$ & 1088 & 1389 & $12.63 \pm 1.14$ & $12.30 \pm 1.15$ \\
\hline 31 & $\begin{array}{l}m / z 41,43,55,57,69,71, \\
239\end{array}$ & $A$ & 80 & 130 & $0.12 \pm 0.04$ & $0.05 \pm 0.04$ \\
\hline 36 & $\begin{array}{l}m / z \text { 41, 43, 55, 57, 69, 71, } \\
239\end{array}$ & $A$ & 48 & 40 & $0.06 \pm 0.04$ & $0.03 \pm 0.04$ \\
\hline 39 & $m / z 41,43,55,60,101,114$ & A & 99 & 58 & $0.35 \pm 0.20$ & $0.19 \pm 0.16$ \\
\hline
\end{tabular}

a Compound classes given in order of elution from GC column.

b Identification method(s). A, GC-MS analysis; B, retention time comparison with authentic synthetic compounds; $C$, retention time increment comparison; $D$, El-mass spectra of TMS derivatives; $E, E / Z$ isomerism unknown.

cAmount in ng of individual constituents per mg of secretion, calculated proportional to the amount of internal standard (octadecane) using their chromatographic peak area ratios.

d Relative amounts calculated as a percentage of the 168 compounds detected by GC-FID. The mean \pm standard deviation is reported. 


\section{References}

1. Mason, R. T. In Biology of Reptilia: Hormones, Brain, and Behavior; Gans, C., Ed.; The University of Chicago Press:Chicago and London, 1992; Vol. 18, Physiology E, p 115.

2. Weldon, P. J.; Flachsbarth, B.; Schulz, S. Nat. Prod. Rep. 2008, 25, 738- 756.

3. Louw, S.; Burger, B. V.; Le Roux, M.; Van Wyk, J. H. J. Chem. Ecol. 2007, 33, 1806- 1818.

4. Lopez, P.; Martin, J. Biochem. Syst. Ecol. 2009, 37, 304- 307.

5. Kopena, R.; Lopez, P.; Martin, J. Z. Naturforsch. (C) 2009, 64, 434- 440.

6. Gabirot, M.; Lopez, P.; Martin, J.; de Fraipont, M.; Heulin, B.; Sinervo, B.; Clobert, J. Biochem. Syst. Ecol. 2008, 36, 539- 544 .

7. Martin, J.; Lopez, P. Chem. Senses 2010, 35, 253- 262.

8. Maderson, P. F. A. Copeia 1967, 743- 752.

9. Maderson, P. F. A. Breviora 1968, 288, 1- 35.

10. Van Wyk, J. H.; Mouton, P. I. N. Amphib. Reptil. 1992, 13, 1- 12.

11. Cordes, I. G.; Mouton, P. I. N.; Van Wyk, J. H. South Afr. J. Zool. 1995, 30, 187- 196.

12. Du Toit, D. A.; Mouton, P. I. N.; Flemming, A. F.; Van Niekerk, A. J. Herpetol. 2005, 39, 384- 388.

13. Dujsebayeva, T. N.; Ananjeva, N. B.; Miroschnichenko, L. V. Amphib. Reptil. 2007, 28, 537-546.

14. McLafferty, F. W.; Turecek, F. Interpretation of Mass Spectra; University Science Books: Mill Valley, CA, 1993.

15. Zaretskii, Z. V. I.; Curtis, J. M.; Brenton, A. G.; Beynon, J. H.; Djerassi, C. Org. Mass Spectrom. 1988, 23) 453459.

16. Zaretskii, Z. V. I.; Curtis, J. M.; Brenton, A. G.; Beynon, J. H.; Djerassi, C. Org. Mass Spectrom. 1988, 23, 460468.

17. Simpson, J. T.; Sharp, T. R.; Wood, W. F.; Weldon, P. J. Z. Naturforsch. (C) 1993, 48, 953- 955.

18. Weldon, P. J.; Ortiz, R.; Sharp, T. R.The Chemical Ecology of Crotaline Snakes. In Biology of the Pitvipers; Campbell, J. A.; Brodie, E. D., Eds.; Selva: Tyler, TX, 1992; pp 309- 319.

19. Salamon, M.; Davies, N. W. J. Chem. Ecol. 1998, 24, 1659- 1676.

20. Van Wyk, J. H. J. Herpetol. 1995, 29, 522- 535.

21. Bancroft, J. D.; Stevens, A. B. Theory and Practice of Histological Techniques; Churchill Livingstone: Edinburg, 1977.

22. Reiter, B.; Burger, B. V.; Dry, J. J. Chem. Ecol. 2003, 29, 2235- 2252.

23. Burger, B. V.; Munro, Z.; Smit, D.; Schmidt, U.; Wu, C.-L.; Tien, F.-C. J. Chromatogr. 1990, 518, $207-214$.

24. Thenot, J.-P.; Horning, E. C. Anal. Lett. 1972, 5, 21-33.

25. Vogel, A. I. Vogel's Textbook of Practical Organic Chemistry, 5th ed.; Longman Group UK Limited, 1989.

26. Hazzard, B. J. Organicum: Practical Handbook of Organic Chemistry; Pergamon Press Ltd.: Oxford, 1973. 